\title{
In-ovo and dietary supplementation of selenium nano-particles influence physiological responses, immunological status and performance of broiler chicks
}

\author{
N.S. Ibrahim ${ }^{1,3}$, E.M. Sabic ${ }^{1}$, M.M. Wakwak', I.E. El-Wardany², Y.M. El-Homosany² \\ and N. El-Deen Mohammad ${ }^{1}$ \\ ${ }^{1}$ Egyptian Atomic Energy Authority, Nuclear Research Center, Biological Application Depatment, Abou-Zabael 13759, Egypt \\ ${ }^{2}$ Ain Shams University, Faculty of Agriculture, Poultry Production Department, Cairo, 11241, Egypt
}

KEY WORDS: blood analysis, carcass yield, chicks, in ovo, nanoparticles, selenium, supplementation

$\begin{array}{lr}\text { Received: } & \text { 12 August } 2019 \\ \text { Revised: } & 5 \text { December } 2019 \\ \text { Accepted: } & 9 \text { March } 2020\end{array}$

${ }^{3}$ Corresponding author:

e-mail: nashaat1977@yahoo.com

\begin{abstract}
This study aimed to explore impacts of in ovo injection and dietary supplementation of selenium nanoparticles (SeNPs) on physiological responses, immunological status and performance of broiler chicks. A total of 210 broiler eggs were divided into 3 in ovo groups: not in ovo injected and in ovo injected with 5 or $10 \mathrm{ppb}$ SeNPs. The hatched chicks from each in ovo group were divided into 2 dietary groups, with or without $10 \mathrm{ppb}$ SeNPs/kg ration for 5 weeks. Live body weight and body weight gain were significantly increased in all SeNPs injected or supplemented groups. Feed conversion ratio for the whole feeding period was improved by SeNPs feed supplementation. Serum triglycerides and malondialdehyde contents were significantly decreased, while high-density lipoprotein cholesterol, immunoglobulin status, reduced glutathione content and glutathione reductase activity were increased by both examined routes of SeNPs delivery. It can be concluded that SeNPs in ovo injection with a dose up to $10 \mathrm{ppb} / \mathrm{egg}$ along with SeNPs diet supplementation at a dose of $10 \mathrm{ppb} / \mathrm{kg}$ had a positive effect on performance and physiological, antioxidant and immunological status of broiler chicks.
\end{abstract}

\section{Introduction}

The producers aim to improve poultry production efficiency and achieve high profitability but have noticed that during commercial production, chicks may be exposed to various microbiological challenges, infection by diseases and oxidative stress, and result in economic and production inefficiencies. Therefore, improving the immune function of chicks by enhancing antioxidant status may contribute to the reduction of morbidity and mortality of birds.

Numerous reports have demonstrated that selenium, an important microelement, acts as a natural biological antioxidant that helps in the protection of cellular membranes against oxidative damage and ameliorates bird growth and health (Suraï and Dvorska, 2002; Levkut et al., 2009; Pilarczyk et al., 2012; Khan et al., 2015; 2016). Unfortunately, traditional forms of selenium supplements, in general, have low levels of absorption and increase toxicity (Raza, 2012; Jamil, 2013; Khan et al., 2016). Furthermore, the lack of this microelement leads to numerous metabolic disorders and diseases through its negative effect on the physiological status of the chicks (Cai et al., 2012). Subsequently, delivering a proper amount of this microelement to chicks' body is important for physiological enzymatic, hormonal and immune processes (Keen et al., 2004). 
The nanoform of selenium particles (SeNPs), is a good example of applied nanotechnology used in the area of nutritional supplements, exhibits advantages and novel properties better than other forms of this microelement, including greater surface activity, higher solubility, mobility, high cellular uptake and excellent bioavailability (Wang et al., 2007; Zhang et al., 2008). Thus, it can be assumed that both SeNPs in ovo injection and SeNPs feed supplementation can be more effective ways of this microelement administration, which would prevent the above-mentioned disadvantages of traditional forms of selenium supplements and elevate the bioavailability and cellular uptake of this element and maintain its health benefits.

Therefore, the objective of the present study was to investigate the effects of SeNPs in ovo injection and dietary supplementation, as well as these two routes of delivery interaction on productive performance, stimulation of the antioxidant defence system and immune response of hatched chicks.

\section{Material and methods}

\section{Poultry ethics}

All of the experiments were carried out according to the guidelines of the Institutional Animal Care and Use Committee for Animal Experiments, which is a member of the Egyptian Network of Research Ethics Committee. The scientific and ethics committee of the Biological Application Department, Egypt) approved all procedures used in this experiment (protocol number 186; date of approval: 14.07.2019).

\section{Experimental procedures}

Two trials were performed at the poultry production farm of the Biological Application Department of the Nuclear Research Center (Egypt) during the period from March to May 2017. The first trial was conducted on eggs with or without SeNPs in ovo administration and the second one was conducted on post-hatch chicks fed a diet with or without SeNPs addition.

\section{First trial}

Eggs collection, incubation and in ovo injection with SeNPs. A total of 210 broiler breeder eggs (Hubbard) weighed between 55 and $60 \mathrm{~g}$ were obtained from broiler egg production El-Tokhy Company (New Salhia, Egypt) from a maternal flock, 54 weeks of age.
Each egg was dry cleaned using a soft toilet paper, then sprayed with a disinfectant solution, dried with soft tissue paper and numbered. The eggs were set vertically in metal trays. Eggs were incubated at $37.8{ }^{\circ} \mathrm{C}$ and $60 \%$ relative humidity (RH). The eggs were turned every $2 \mathrm{~h}$ through $45^{\circ}$ (12 times a day) up to 18 days. At day 14 of incubation the eggs were candled using a candling lamp in a darkened room, and the infertile eggs or eggs containing dead embryos were excluded.

Eggs with live embryos were randomly divided into 3 experimental in ovo groups (65 eggs in each): not in ovo injected (control group) and in ovo injected into the air cell with 5 or $10 \mathrm{ppb}$ SeNPs diluted in $100 \mu \mathrm{l}$. SeNPs were obtained from the Department of Physics, Faculty of Science, Mansoura University (Egypt). On day 18, the eggs were transferred to the hatcher set at $37^{\circ} \mathrm{C}$ and $90 \% \mathrm{RH}$ for up to 21 days.

The injection procedure into the air cell was performed as described by Bhanja et al. (2004). The eggs remained outside the incubator for approximately 15 min for injection. Prior injection, both the working bench and the eggs were disinfected with $70 \%$ ethanol, the shell was punched at the wide end of the egg to make a hole with a 21-ga needle. Then, the eggs were injected with a 23-ga needle, the site of injection was sealed with adhesive tape and the eggs returned again to the hatcher for the hatching process. The hatched chicks within each group were recorded and weighed individually immediately after hatching using an electronic balance with accuracy $\pm 0.01 \mathrm{~g}$.

\section{Second trial}

Chicks. Sixty hatched chicks per each group from the first trial were randomly equally divided into two dietary groups (30 chicks each) each assigned to three pens (10 chicks per pen). Chicks in two dietary groups were fed diet with or without SeNPs supplementation at a dose of $10 \mathrm{ppb}$ per $\mathrm{kg}$ of ration. SeNPs were added to the ration by diluting $1 \mathrm{ml}$ of solution with the concentration of $10 \mathrm{ppb}$ SeNPs in $20 \mathrm{ml}$ of distilled water. The obtained solution was spread per $100 \mathrm{~g}$ of diet and mixed well with another $100 \mathrm{~g}$ to reach to homogeneous kilogram ration.

So in the second trial six experimental groups were obtained: R1 $(0 \times 0)$ and R2 $(0 \times 10)$ - groups without SeNPs in ovo injection and without or with SeNPs dietary supplementation, respectively; R3 $(5 \times 0)$ and R4 $(5 \times 10)-$ groups with SeNPs in ovo injection at dose of $5 \mathrm{ppb}$ and without or with SeNPs dietary supplementation, respectively; R5 $(10 \times 0)$ and R6 $(10 \times 10)-$ groups with SeNPs in ovo injection at dose of $10 \mathrm{ppb}$ and without or with SeNPs dietary supplementation, respectively. 


\section{Housing and management}

All experimental chicks were grown in metal cages $(100 \times 60 \times 50 \mathrm{~cm}$; length $\times$ width $\times$ height $)$ equipped with manual feeder and automatic nipple drinker. The birds were kept at the same managerial, controlled, clean and hygienic environmental conditions. All groups were allowed ad libitum access to water and feed. Throughout the first week, the chicks were exposed to $24 \mathrm{~h}$ of light per day, then the exposure was reduced to $22 \mathrm{~h}$ per day for the rest of experimental period.

Vaccination against the Newcastle Disease Virus (NDV) was performed on days 21 and 28 of age using an eye dropper (Live Lasota strain; KBNP Inc., Hungnam, South Korea).

\section{Experimental diet}

The basal diet was purchased from Salah Attia Co. (Tafahna El-Ashraf, Egypt) and was formulated to meet the recommendations of National Research Council for broiler chicks (NRC, 1994). The basal diet composition and calculated chemical analysis are presented in Table 1.

Table 1. Basal diet ingredients and calculated chemical composition

\begin{tabular}{lcc}
\hline Indices & Starter & Grower \\
\hline Ingredients, $\%$ & & \\
yellow maize & 58.50 & 62.50 \\
soybean meal (44\%) & 26.00 & 23.94 \\
maize gluten meal (62\%) & 10.00 & 7.00 \\
vegetable oil & 1.50 & 2.50 \\
limestone & 1.12 & 1.23 \\
di-calcium phosphate & 1.75 & 1.70 \\
premix & 0.30 & 0.30 \\
NaCl & 0.30 & 0.30 \\
L-lysine & 0.36 & 0.36 \\
DL-methionine & 0.17 & 0.17 \\
Calculated composition, g/kg & & \\
ME, kcal/kg & 3058 & 3120 \\
crude protein & 22.45 & 20.20 \\
calcium & 0.93 & 0.95 \\
non-phytate phosphorus & 0.46 & 0.45 \\
methionine & 0.62 & 0.57 \\
lysine & 1.28 & 1.20 \\
TSAA & 1.00 & 0.90 \\
\hline
\end{tabular}

${ }^{1}$ provides each $\mathrm{kg}$ of diet: IU: vit. A 12000 , vit. $D_{3} 5000$; mg: vit. E 130, vit. $K_{3} 3.605$, vit. $B_{1} 3$, vit. $B_{2} 8$, vit. $B_{6} 4.95$,vit. $B_{12} 0.17$, niacin 60 , folic acid 2.083, D-Biotin 200, calcium D-pantothenate 18.333, copper 80 , iodine 2 , selenium 150 , iron 80 , manganese 100 , zinc 80 , cobalt $500 \mathrm{mg}$ per kg; ME - metabolizable energy; TSAA - total sulphur-containing amino acids

\section{Productive performance parameters}

Live body weight (LBW) per replicate was recorded individually very week in the early morning before food and water administration using a digital platform balance. Average daily body weight gain (BWG) was calculated weekly and the overall BWG was calculated for the whole experimental period (35 days) at the end of the experimental.

\section{Feed intake and feed conversion ratio}

Feed intake per replicate was calculated at the end of a given period by subtraction residual feed (g) from the offered amount. That value was divided by the number of birds per replicate in order to calculate the average amount of feed intake per bird (FI). Feed conversion ratio (FCR) was also calculated $(\mathrm{FCR}=\mathrm{g}$ feed $/ \mathrm{g}$ body weight gain).

\section{Carcass characteristics}

At the end of the 35-day experimental period, three representative birds were chosen randomly from each pen. Before slaughtering, assigned birds were fasted for $12 \mathrm{~h}$ and then individually weighed, slaughtered, defeathered, opened and the hot carcass was weighed and recorded. Edible offals (liver, heart and gizzard) and non-edible offals (proventriculus, thymus, bursa of Fabricius and spleen) were separately weighed and recorded. Carcass yield was calculated as follows:

carcass yield $=$

empty carcass weight, $\mathrm{g}+$ edible offals weight, $g \times 100$. live pre-slaughtering weight, $g$

\section{Physiological and biochemical parameters}

At the end of the experimental period (35 days of age), 3 birds per pen were randomly selected and two blood samples were collected from each bird during slaughtering time. One sample was collected into heparinised tubes to perform the haematological parameters analysis (blood haemoglobin $(\mathrm{Hb})$, erythrocytes (RBCs) and leukocytes (WBCs) number, packed cell volume (PCV), mean corpuscular haemoglobin $(\mathrm{MCH})$, mean corpuscular haemoglobin concentration (MCHC) and mean corpuscular volume (MCV)). The second sample of blood was collected into non-heparinised tubes and centrifuged at $3400 \mathrm{~g}$ for $6 \mathrm{~min}$ and the sera were separated in Eppendorf tubes and stored at $-20{ }^{\circ} \mathrm{C}$ until further biochemical measurements.

For humoral immune response assessment, on days 28 and 35 of age ( 7 and 14 days after vaccination, respectively), blood samples were collected from the wing vein of birds into heparinised tubes, and centrifuged at $2500 \mathrm{~g}$ for $10 \mathrm{~min}$ and the plasma was separated and stored at $-20^{\circ} \mathrm{C}$. 


\section{Blood and serum biochemical analysis}

Serum total proteins, albumin, globulin, glucose, triglycerides, total cholesterol, high-density lipoprotein cholesterol (HDL-C), low-density lipoprotein cholesterol (LDL-C), uric acid and creatinine concentrations, albumin to globulin ratio (A:G ratio) and aspartate aminotransferase (AST), alanine aminotransferase (ALT) and alkaline phosphates (ALP) activities were measured with a spectrophotometer (UV1601; Shimadzu, Kyoto, Japan) using commercial kits produced by (Stanbio Laboratory, Boerne, TX, USA). Serum triiodothyronine $\left(\mathrm{T}_{3}\right)$ hormone concentration was measured by radioimmunoassay (RIA) kit produced by Institute of Isotopes Ltd. (Konkoly, Hungary) and samples were counted on Packard Gamma Counter (GMI, Ramsey, MN, USA).

\section{Antioxidant status}

Serum content of reduced glutathione (GSH) and malondialdehyde (MDA) and activity of glutathione reductase were determined using commercial kits supplied by Spinreact Co. (Santa Coloma, Spain).

\section{Humoral immune response: antibody production against Newcastle Disease Virus(NDV)}

The anti-Newcastle Disease Virus (NDV) titer in serum collected on days 28 and 35 of age was determined by a haemagglutination inhibition test using ELISA test kit (FLOCK TYPE recNDV, Labor Diagnostik, Leipzig, Germany) as described by Allan and Gough (1974).

\section{Plasma immunoglobulin concentrations}

Plasma immunoglobulin (Ig) A, IgM, IgG and total Ig concentrations were determined using chicken-specific IgA, IgM and IgG ELISA quantitation kits (Bethyl Laboratories Inc., Montgomery, TX, USA). Total plasma Ig concentration was calculated by the sum of the respective serum IgA, IgM and IgG concentrations (Mountzouris et al., 2010).

\section{Statistical analysis}

Data of the study for all variables were subjected to analysis of variance (ANOVA) as a completely randomized design using the procedure of SPSS software ver. 18 (2010; SPSS Inc., Chicago, IL, USA). Multiple range test method was used to test the statistical differences among treatments according to Duncan (1955). The following model was used:

$$
\mathrm{Y}_{\mathrm{ijk}}=\mu+\mathrm{O}_{\mathrm{i}}+\mathrm{I}_{\mathrm{j}}+\mathrm{OI}_{\mathrm{ij}}+\mathrm{e}_{\mathrm{ijk}}
$$

where: $Y_{\mathrm{ijk}}-$ the observation, $\mu$ - the overall mean, $\mathrm{O}_{\mathrm{i}}$ - fixed effect of $\mathrm{i}^{\text {th }}$ in ovo level $(\mathrm{i}=0,5$ or $10 \mathrm{ppb} / \mathrm{egg}) ; \mathrm{I}_{\mathrm{j}}$ - fixed effect of $\mathrm{j}^{\text {th }}$ SeNPs diet level $(\mathrm{j}=0$ or $10 \mathrm{ppb}), O \mathrm{I}_{\mathrm{ij}}-$ interaction effect of $\mathrm{i}^{\text {th }}$ in ovo injection level with $\mathrm{j}^{\text {th }}$ diet supplementation level, and $\mathrm{e}_{\mathrm{ijk}}$ - error of the model.

\section{Results and discussion}

Live body weight and body weight gain. It was shown that live body weight (LBW) and body weight gain (BWG) of Hubbard chicks were influenced by SeNPs in ovo injection and feed supplementation (Table 2). But the interaction between these two delivery routes was not statistically significant. Both of SeNPs delivery routes significantly improved LBW. The in ovo delivery increased LBW in the $1^{\text {st }}$, $2^{\text {nd }}, 3^{\text {rd }}$ and $5^{\text {th }}$ week regardless of the used dose $(P<0.001, P<0.007, P<0.001$ and $P<0.03$, respectively for each week). The SeNPs feed supplementation increased LBW in the $3^{\text {rd }}, 4^{\text {th }}$ and $5^{\text {th }}$ week $(P<0.027, P<0.001$ and $P<0.001$, respectively). Although the interaction between the two examined delivery routes was not stated for LBW, it was found that the highest values of LBW were observed in R6 $(10 \times 10)$ and R4 $(5 \times 10)$ groups during all experimental periods and the ratio of increment in these groups was 8.97 and 7.24, respectively. The overall BWG was also increased by both routes of SeNPs delivery $(P<0.035$ and $P<0.001$, respectively for in ovo and dietary delivery). The improvements in LBW and BWG in treated groups may confirm the important role of selenium as a structural component of 5'-deiodinase, which is a key enzyme participating in the thyroxine $\left(\mathrm{T}_{4}\right)$ conversion to the active triiodothyronine $\left(\mathrm{T}_{3}\right)$, which may influence the body energy and protein uptake, and thus may regulate chick growth (Jianhua et al., 2000). This may also be due to the fact that selenium deficiency leads to nutritional muscular dystrophy and the selenium supplementation prevents such a negative effect. This is in agreement with Cantor et al. (1982) who concluded that selenium supplementation in turkey poults increased body weight and reduced the incidence of gizzard myopathy. A similar trend was also reported by Zhou and Wang (2011) who showed significant improvement in the growth performance of broiler chicks by SeNPs supplementation up to $0.5 \mathrm{mg} / \mathrm{kg}$ basal diet. Likewise, Heindl et al. (2010) and Rozbicka-Wieczorek et al. (2012) reported a beneficial effects of selenium-enriched yeast addition into feed on body weight of broiler chickens. 
Table 2. Effect of in ovo injection and feed supplementation with selenium nanoparticles (SeNPs) on live body weight and body weight gain of broiler chicks at different periods

\begin{tabular}{|c|c|c|c|c|c|c|c|}
\hline \multirow{2}{*}{ Indices } & \multicolumn{6}{|c|}{ Live body weight, $g$} & \multirow{2}{*}{$\begin{array}{l}\text { Body weight } \\
\text { gain, g/bird/day } \\
1-35 \text { day }\end{array}$} \\
\hline & initial & $1^{\text {st }}$ week & $2^{\text {nd }}$ week & $3^{\text {rd }}$ week & $4^{\text {th }}$ week & $5^{\text {th }}$ week & \\
\hline \multicolumn{8}{|c|}{$\begin{array}{l}\text { Main factors } \\
\text { in ovo injection (I) }\end{array}$} \\
\hline 0 & 45.3 & $153^{b}$ & $411^{b}$ & $796^{b}$ & 1367 & $1977^{b}$ & $55.2^{b}$ \\
\hline 5 & 45.7 & $168^{a}$ & $439^{a}$ & $857^{a}$ & 1391 & $2038^{a}$ & $56.9^{\mathrm{a}}$ \\
\hline 10 & 45.4 & $164^{\mathrm{a}}$ & $443^{a}$ & $856^{a}$ & 1388 & $2052^{a}$ & $57.3^{\mathrm{a}}$ \\
\hline$P$-value & 0.759 & 0.001 & 0.007 & 0.001 & 0.376 & 0.032 & 0.035 \\
\hline SEM & 0.35 & 2.49 & 7.74 & 11.63 & 13.54 & 21.48 & 0.61 \\
\hline \multicolumn{8}{|c|}{ feed supplementation (S) } \\
\hline 0 & 45.6 & 162 & 424 & $821^{b}$ & $1355^{b}$ & $1977^{b}$ & $55.2^{b}$ \\
\hline 10 & 45.4 & 162 & 438 & $851^{a}$ & $1409^{a}$ & $2068^{a}$ & $57.8^{\mathrm{a}}$ \\
\hline$P$-value & 0.676 & 0.909 & 0.133 & 0.027 & 0.001 & 0.001 & 0.001 \\
\hline SEM & 0.29 & 2.04 & 6.32 & 9.50 & 11.06 & 17.55 & 0.50 \\
\hline \multicolumn{8}{|l|}{ Interaction $(I \times S)$} \\
\hline $\mathrm{R} 1(0 \times 0)$ & 45.5 & 153 & 414 & 790 & 1351 & 1936 & 54.1 \\
\hline $\mathrm{R} 2(0 \times 10)$ & 45.2 & 154 & 408 & 803 & 1383 & 2018 & 56.4 \\
\hline R3 $(5 \times 0)$ & 45.7 & 166 & 429 & 837 & 1368 & 2001 & 55.8 \\
\hline $\mathrm{R} 4(5 \times 10)$ & 45.7 & 169 & 449 & 876 & 1414 & 2076 & 58.0 \\
\hline $\mathrm{R} 5(10 \times 0)$ & 45.5 & 165 & 430 & 837 & 1346 & 1994 & 55.6 \\
\hline $\mathrm{R} 6(10 \times 10)$ & 45.4 & 163 & 456 & 874 & 1430 & 2110 & 59.0 \\
\hline$P$-value & 0.962 & 0.780 & 0.282 & 0.682 & 0.391 & 0.780 & 0.765 \\
\hline SEM & 0.49 & 3.53 & 10.95 & 16.45 & 19.15 & 30.38 & 0.86 \\
\hline
\end{tabular}

a,b - means with different superscripts within the same column for each main factor or interaction separately are significantly different $(P \leq 0.05)$; SEM - standard error of means

Also Khazraie et al. (2015) showed a significant increase in the weight gain of quail chicks fed diet supplemented with SeNPs compared to control one.

Feed intake and feed conversion ratio. As shown (Table 3 ) the average daily FI of broiler chicks was significantly $(P<0.05)$ for all weeks except $3^{\text {rd }}$ week influenced by in ovo injection of SeNPs, and the FI values were higher in the injected groups especially in the first 3 weeks after the hatch. The total feed intake (TFI) was higher only when the higher dose of SeNPs was injected compare to non-injected group. However, in case of using SeNPs as feed additive no significant difference in average daily FI and TFI values between the treated and control group was stated. There was also a significant interaction between the two examined routes of SeNPs delivery for the average daily FI (except for the first week) and TFI. The highest value of FI was observed in R6 $(10 \times 10)$ group, which was both in ovo injected with10 ppb SeNPs per egg and dietary supplemented with $10 \mathrm{ppb}$ SeNPs per $\mathrm{kg}$ of feed. Nevertheless, a different trend was noted for FCR which was influenced by SeNPs feed supplementation indicating significant improvement, except the first and second growing periods (0-7 and 8-14 day, respectively). The in ovo injection did not exert effect on FCR except the first period ( $0-7$ day) in which the FCR values were increased in the group with a higher dose injection. The interaction between the two delivery routes was significant only in the period from day 15 to 21 . The most favourable FCR values for the whole experimental period were observed for groups $\mathrm{R} 4(5 \times 10), \mathrm{R} 2(0 \times 10)$ and $\mathrm{R} 6(10 \times 10)$ being 1.40 , 1.41 and 1.45 , respectively.

The improvement in FCR may result from the higher utilization of SeNPs associated with the unique properties of nanoform selenium, such as greater surface activity, higher solubility, mobility, high cellular uptake and excellent bioavailability (Wang et al., 2007; Zhang et al., 2008). It is also known that selenium is involved in the regulation of the energy metabolism and the metabolism of the essential fatty acids, and purinic and pyrimidinic bases (Ebeid, 2013). The selenium influence on $T_{3}$ synthesis may be also of important notice as $\mathrm{T}_{3}$ is a main hormone controlling the body energy and protein anabolism. In agreement with the present results, Saleh (2014) indicated that broiler chickens feed with the dietary mixture of Aspergillus probiotic and SeNPs significantly improved FCR and decreased FI. Also, Chen et al. (2013) reported that yeast selenium supplementation $(0.15$ or 
Table 3. Effect of in ovo injection and feed supplementation with selenium nanoparticles (SeNPs) on feed intake and feed conversion ratio of broiler chicks at different periods

\begin{tabular}{|c|c|c|c|c|c|c|c|c|c|c|c|c|}
\hline \multirow{3}{*}{ Indices } & \multicolumn{6}{|c|}{ Feed intake, g/bird/day } & \multicolumn{6}{|c|}{ Feed conversion ratio, $\mathrm{g}$ feed/g gain } \\
\hline & $0-7$ & $8-14$ & $15-21$ & $22-28$ & $29-35$ & $1-35$ & $0-7$ & $8-14$ & $15-21$ & $22-28$ & $29-35$ & $1-35$ \\
\hline & \multicolumn{6}{|l|}{ day } & \multicolumn{6}{|l|}{ day } \\
\hline \multicolumn{13}{|c|}{$\begin{array}{l}\text { Main factors } \\
\text { in ovo injection (I) }\end{array}$} \\
\hline 0 & $18.3^{\mathrm{c}}$ & $49.4^{c}$ & $79.9^{\mathrm{b}}$ & 122 & $133^{b}$ & $80.7^{b}$ & $1.18^{b}$ & 1.34 & 1.46 & 1.51 & $1.53^{\mathrm{a}}$ & 1.46 \\
\hline 5 & $20.3^{b}$ & $52.8^{\mathrm{b}}$ & $85.8^{\mathrm{a}}$ & 118 & $130^{\mathrm{b}}$ & $81.5^{b}$ & $1.17^{\mathrm{b}}$ & 1.37 & 1.44 & 1.55 & $1.41^{\mathrm{b}}$ & 1.43 \\
\hline 10 & $22.1^{\mathrm{a}}$ & $54.3^{\mathrm{a}}$ & $84.4^{\mathrm{a}}$ & 119 & $139^{a}$ & $83.7^{\mathrm{a}}$ & $1.31^{\mathrm{a}}$ & 1.36 & 1.43 & 1.56 & $1.47^{\mathrm{ab}}$ & 1.46 \\
\hline$P$-value & 0.002 & 0.003 & 0.001 & 0.052 & 0.001 & 0.002 & 0.004 & 0.786 & 0.670 & 0.379 & 0.035 & 0.208 \\
\hline SEM & 0.30 & 0.33 & 0.89 & 1.21 & 1.26 & 0.48 & 0.025 & 0.03 & 0.019 & 0.03 & 0.029 & 0.012 \\
\hline \multicolumn{13}{|c|}{ feed supplementation (S) } \\
\hline 0 & 20.2 & 51.9 & 83.0 & 120 & 134 & 81.8 & 1.22 & 1.39 & $1.47^{\mathrm{a}}$ & 1.58 & $1.51^{\mathrm{a}}$ & $1.48^{\mathrm{a}}$ \\
\hline 10 & 20.3 & 52.4 & 83.8 & 120 & 134 & 82.1 & 1.22 & 1.33 & $1.42^{b}$ & 1.51 & $1.42^{b}$ & $1.42^{b}$ \\
\hline$P$-value & 0.687 & 0.252 & 0.476 & 0.938 & 0.946 & 0.629 & 0.856 & 0.137 & 0.042 & 0.065 & 0.024 & 0.001 \\
\hline SEM & 0.247 & 0.268 & 0.726 & 0.990 & 1.03 & 0.390 & 0.02 & 0.025 & 0.015 & 0.024 & 0.024 & 0.01 \\
\hline \multicolumn{13}{|l|}{ Interaction $(\mathrm{I} \times \mathrm{S})$} \\
\hline $\mathrm{R} 1(0 \times 0)$ & 18.6 & $50.1^{\mathrm{c}}$ & $79.9^{c}$ & $125^{\mathrm{a}}$ & $136^{\mathrm{ab}}$ & $81.9^{b}$ & 1.22 & 1.35 & $1.50^{\mathrm{a}}$ & 1.56 & 1.62 & 1.52 \\
\hline $\mathrm{R} 2(0 \times 10)$ & 18.0 & $48.6^{d}$ & $80.0^{c}$ & $121^{\mathrm{ab}}$ & $130^{\mathrm{bc}}$ & $79.5^{c}$ & 1.15 & 1.33 & $1.42^{b c}$ & 1.45 & 1.44 & 1.41 \\
\hline $\mathrm{R} 3(5 \times 0)$ & 20.2 & $52.7^{\mathrm{b}}$ & $87.5^{\mathrm{a}}$ & $121^{\mathrm{ab}}$ & $128^{c}$ & $81.9^{b}$ & 1.17 & 1.41 & $1.50^{\mathrm{a}}$ & 1.6 & 1.42 & 1.47 \\
\hline $\mathrm{R} 4(5 \times 10)$ & 20.5 & $53.0^{\mathrm{b}}$ & $84.2^{\mathrm{ab}}$ & $116^{\mathrm{bc}}$ & $132^{\mathrm{bc}}$ & $81.1^{b c}$ & 1.16 & 1.33 & $1.38^{c}$ & 1.51 & 1.4 & 1.40 \\
\hline $\mathrm{R} 5(10 \times 0)$ & 21.7 & $53.0^{\mathrm{b}}$ & $81.7^{\mathrm{bc}}$ & $114^{c}$ & $138^{a}$ & $81.7^{\mathrm{bc}}$ & 1.27 & 1.5 & $1.40^{\circ}$ & 1.57 & 1.50 & 1.47 \\
\hline $\mathrm{R} 6(10 \times 10)$ & 22.5 & $55.5^{\mathrm{a}}$ & $87.2^{\mathrm{a}}$ & $124^{a}$ & $139^{a}$ & $85.7^{\mathrm{a}}$ & 1.34 & 1.42 & $1.46^{\mathrm{ab}}$ & 1.56 & 1.44 & 1.45 \\
\hline$P$-value & 0.308 & 0.004 & 0.014 & 0.002 & 0.047 & 0.001 & 0.225 & 0.691 & 0.013 & 0.492 & 0.164 & 0.061 \\
\hline SEM & 0.43 & 0.46 & 1.26 & 1.72 & 1.78 & 0.68 & 0.035 & 0.043 & 0.027 & 0.042 & 0.041 & 0.017 \\
\hline
\end{tabular}

a-d - means with different superscripts within the same column for each main factor or interaction separately are significantly different $(P \leq 0.05)$; SEM - standard error of means

$0.30 \mathrm{mg} / \mathrm{kg}$ ) could significantly increase broiler daily gains and FCR in comparison to the same doses of sodium selenite. Similarly, Zhou and Wang (2011) showed that SeNPs supplementation up to $0.5 \mathrm{mg}$ per $\mathrm{kg}$ of the basal broiler diet effectively improved FCR.

Carcass characteristics. All the examined carcass traits (carcass, breast, thigh, total edible, heart, gizzard, liver, spleen, thymus, bursa of Fabricius and carcass yield as percentage of LBW) were not significantly affected $(P>0.05)$ by in ovo injection with different doses of SeNPs or feed SeNPs supplementation, except the carcass weight that was significantly $(P<0.05)$ affected by feed supplementation (Table 4). The interaction between the two examined delivery routes was significant $(P<0.01)$ for the carcass yield, and the highest carcass yield was observed in R4 $(5 \times 10)$ followed by R2 $(0 \times 10)$ and R6 $(10 \times 10)$ groups.

In line with the present results, Khazraie et al. (2015) indicated no significant effect of diets with SeNPs addition on carcass composition of chicks. Also Biswas et al. (2006) reported that selenium supplementation did not have any effect on liver and spleen weights. In the same trend, Peng et al. (2009) and Cai et al. (2012) reported no significant differences in the relative weight of immune organs (thymus, bursa of Fabricius and spleen) of broiler chicks receiving SeNPs with the diet.

Haematological parameters. The results revealed that both SeNPs delivery routes and the interaction between did not affected the examined blood constitute parameters (WBCs, RBCs, Hb, PCV, $\mathrm{MCH}, \mathrm{MCHC}$ and MCV) (Table 5). Lack of significant changes in haematological indices may reflex that no physiologically stressful condition was introduced in treated chicks. Moreover, the obtained haematological results can be a good indicator that chicks were fed on a sufficient doses of SeNPs in the present study.

The obtained findings are not partially in agreement with the results of Boostani et al. (2015) who showed a significant difference in total WBCs number in broiler chicks fed $0.3 \mathrm{mg} / \mathrm{kg}$ SeNPs under oxidative stress conditions. The same authors also showed that no difference was found for the number of $\mathrm{RBCs}, \mathrm{Hb}, \mathrm{PCV}, \mathrm{MCH}$ and $\mathrm{MCHC}$, which is in line with the results of the present study. Similarly, Chen et al. (2013) showed no significant difference in blood biochemical indexes (WBCs, RBCs, $\mathrm{Hb}$ and $\mathrm{PCV}$ ) in broilers fed different selenium sources. However, Khazraie et al. (2015) reported 
Table 4. Effect of in ovo injection and feed supplementation with selenium nanoparticles (SeNPs) on carcass characteristics of broiler chicks

\begin{tabular}{|c|c|c|c|c|c|c|c|c|c|c|c|c|}
\hline \multirow{2}{*}{ Indices } & \multirow{2}{*}{ LBW, g } & \multicolumn{10}{|c|}{ Carcass traits, $\%$} & \multirow{2}{*}{$\begin{array}{l}\text { Carcass } \\
\text { yield, \% }\end{array}$} \\
\hline & & carcass & heart & gizzard & liver & giblets & thigh & breast & spleen & thymus & bursa & \\
\hline \multicolumn{13}{|l|}{ Main factors } \\
\hline \multicolumn{13}{|c|}{ in ovo injection (I) } \\
\hline 0 & 2070 & 72.5 & 0.48 & 1.11 & 2.59 & 4.18 & 29.7 & 42.6 & 0.12 & 0.46 & 0.19 & 76.7 \\
\hline 5 & 2096 & 72.2 & 0.48 & 1.16 & 2.38 & 3.86 & 29.1 & 41.8 & 0.10 & 0.42 & 0.18 & 76.2 \\
\hline 10 & 2055 & 72.2 & 0.48 & 1.21 & 2.32 & 3.97 & 29.1 & 41.5 & 0.11 & 0.46 & 0.19 & 76.1 \\
\hline$P$-value & 0.176 & 0.938 & 0.983 & 0.332 & 0.232 & 0.422 & 0.627 & 0.762 & 0.305 & 0.484 & 0.743 & 0.844 \\
\hline SEM & 14.51 & 0.73 & 0.02 & 0.05 & 0.11 & 0.14 & 0.53 & 0.78 & 0.01 & 0.02 & 0.01 & 0.70 \\
\hline \multicolumn{13}{|c|}{ feed supplementation (S) } \\
\hline 0 & $1970^{b}$ & $71.1^{\mathrm{b}}$ & 0.47 & 1.19 & 2.31 & 3.97 & 28.9 & 42.0 & 0.11 & 0.44 & 0.19 & $75.1^{\mathrm{b}}$ \\
\hline 10 & $2178^{a}$ & $73.4^{\mathrm{a}}$ & 0.49 & 1.12 & 2.55 & 4.03 & 29.9 & 42.0 & 0.11 & 0.45 & 0.18 & $77.6^{\mathrm{a}}$ \\
\hline$P$-value & 0.00 & 0.016 & 0.278 & 0.218 & 0.087 & 0.203 & 0.954 & 0.143 & 0.451 & 0.799 & 0.932 & 0.008 \\
\hline SEM & 11.85 & 0.59 & 0.02 & 0.04 & 0.09 & 0.11 & 0.44 & 0.64 & 0.004 & 0.02 & 0.01 & 0.57 \\
\hline \multicolumn{13}{|l|}{ Interaction $(I \times S)$} \\
\hline $\mathrm{R} 1(0 \times 0)$ & 1955 & 72.1 & 0.49 & 1.11 & 2.65 & 4.25 & 28.9 & 42.8 & 0.12 & 0.48 & 0.19 & $76.3^{\mathrm{abc}}$ \\
\hline $\mathrm{R} 2(0 \times 10)$ & 2185 & 72.9 & 0.47 & 1.11 & 2.53 & 4.11 & 30.4 & 42.4 & 0.11 & 0.45 & 0.20 & $77.0^{\mathrm{ab}}$ \\
\hline $\mathrm{R} 3(5 \times 0)$ & 2020 & 69.4 & 0.44 & 1.22 & 2.20 & 3.86 & 28.0 & 41.3 & 0.10 & 0.40 & 0.18 & $73.2^{\mathrm{c}}$ \\
\hline $\mathrm{R} 4(5 \times 10)$ & 2172 & 74.9 & 0.51 & 1.10 & 2.57 & 4.18 & 30.2 & 42.3 & 0.11 & 0.45 & 0.17 & $79.0^{\mathrm{a}}$ \\
\hline $\mathrm{R} 5(10 \times 0)$ & 1935 & 71.8 & 0.46 & 1.25 & 2.09 & 3.80 & 29.9 & 41.9 & 0.10 & 0.46 & 0.19 & $75.6^{\mathrm{bc}}$ \\
\hline $\mathrm{R} 6(10 \times 10)$ & 2176 & 72.5 & 0.50 & 1.16 & 2.55 & 4.14 & 28.9 & 41.1 & 0.11 & 0.45 & 0.18 & $76.7^{\mathrm{ab}}$ \\
\hline$P$-value & 0.103 & 0.062 & 0.323 & 0.650 & 0.177 & 0.262 & 0.717 & 0.126 & 0.701 & 0.436 & 0.836 & 0.040 \\
\hline SEM & 20.52 & 1.03 & 0.03 & 0.07 & 0.16 & 0.16 & 0.75 & 1.11 & 0.01 & 0.03 & 0.02 & 0.98 \\
\hline
\end{tabular}

LBW - live body weight; ${ }^{a-c}$ - means with different superscripts within the same column for each main factor or interaction separately are significantly different $(P \leq 0.05)$; SEM - standard error of means

Table 5. Effect of in ovo injection and feed supplementation with selenium nanoparticles (SeNPs) on blood haematological parameters of broiler chicks

\begin{tabular}{|c|c|c|c|c|c|c|c|}
\hline Indices & $\mathrm{RBC}, \times 10^{6} / \mathrm{mm}^{3}$ & $\mathrm{WBC}, \times 10^{3} / \mathrm{mm}^{3}$ & $\mathrm{Hb}, \mathrm{mg} / \mathrm{dl}$ & PCV, \% & $\mathrm{MCH}, \mathrm{pg}$ & $\mathrm{MCHC}, \mathrm{g} / 100 \mathrm{ml}$ & $M C V,\left.\mu\right|^{3}$ \\
\hline \multicolumn{8}{|l|}{ Main factors } \\
\hline \multicolumn{8}{|c|}{ in ovo injection (I) } \\
\hline 0 & 4.99 & 23.5 & 13.2 & 33.3 & 26.5 & 39.7 & 66.8 \\
\hline 5 & 5.08 & 23.3 & 13.2 & 34.2 & 26.3 & 38.7 & 67.6 \\
\hline 10 & 4.95 & 23.5 & 13.3 & 33.2 & 27.0 & 40.0 & 67.5 \\
\hline$P$-value & 0.90 & 0.73 & 0.98 & 0.69 & 0.84 & 0.64 & 0.93 \\
\hline SEM & 0.21 & 1.12 & 0.42 & 0.87 & 0.92 & 1.03 & 1.56 \\
\hline \multicolumn{8}{|c|}{ feed supplementation (S) } \\
\hline 0 & 5.16 & 23.2 & 13.3 & 34.1 & 25.9 & 39.0 & 66.5 \\
\hline 10 & 4.85 & 24.3 & 13.2 & 33.0 & 27.2 & 40.0 & 68.2 \\
\hline$P$-value & 0.23 & 0.41 & 0.78 & 0.29 & 0.25 & 0.35 & 0.46 \\
\hline SEM & 0.18 & 0.91 & 0.34 & 0.71 & 0.75 & 0.84 & 1.27 \\
\hline \multicolumn{8}{|l|}{ Interaction $(I \times S)$} \\
\hline $\mathrm{R} 1(0 \times 0)$ & 4.99 & 22.7 & 13.2 & 34.3 & 26.5 & 38.5 & 68.8 \\
\hline $\mathrm{R} 2(0 \times 10)$ & 4.99 & 24.3 & 13.7 & 32.3 & 26.6 & 41.0 & 64.8 \\
\hline $\mathrm{R} 3(5 \times 0)$ & 5.37 & 23.0 & 13.3 & 35.0 & 25.1 & 38.2 & 65.6 \\
\hline $\mathrm{R} 4(5 \times 10)$ & 4.80 & 23.7 & 13.0 & 33.3 & 27.3 & 39.3 & 69.6 \\
\hline $\mathrm{R} 5(10 \times 0)$ & 5.13 & 24.0 & 13.4 & 33.0 & 26.2 & 40.5 & 64.9 \\
\hline $\mathrm{R} 6(10 \times 10)$ & 4.76 & 25.0 & 13.2 & 33.3 & 27.8 & 39.6 & 70.2 \\
\hline$P$-value & 0.65 & 0.95 & 0.95 & 0.61 & 0.71 & 0.12 & 0.51 \\
\hline SEM & 0.30 & 1.58 & 0.59 & 1.23 & 1.30 & 1.46 & 2.21 \\
\hline
\end{tabular}

$\mathrm{RBC}$ - red blood cells; WBC - white blood cells; $\mathrm{Hb}$ - haemoglobin value; PCV - packed cell volume; $\mathrm{MCH}$ - mean corpuscular haemoglobin; $\mathrm{MCHC}$ - mean corpuscular haemoglobin concentration; MCV - mean corpuscular volume; SEM - standard error of means 


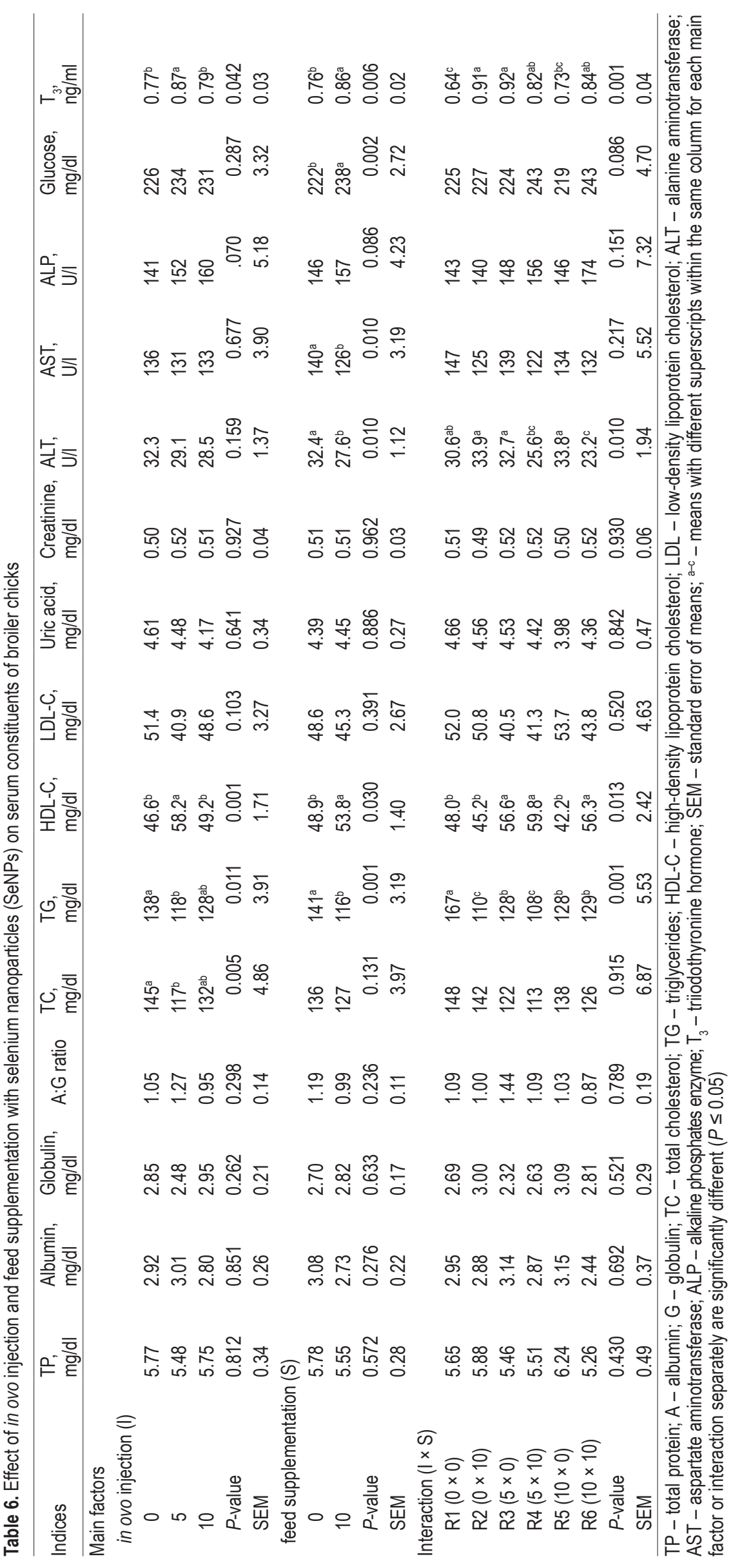


a significant increase in haemoglobin concentration in quails fed diet supplemented 0.2 mg SeNPs.

Blood biochemical analysis. The results of serum total protein, albumin and globulin concentrations and A:G ratio showed no statistical effect of both examined routes of SeNPs administration as well as no significant interaction between these routes in the Hubbard broiler chicks (Table 6). The obtained results are in accordance with Yang et al. (2012) who observed no effect of selenium in the diet on the serum total protein and globulin levels in chicks. The same results were observed by Selim et al. (2015) who indicated no significant effect on plasma total protein, globulin and albumin contents in broiler chicks fed diet supplemented with SeNPs. In contrary, Mohamed et al. (2016) showed a significant increase in plasma total protein and globulin concentrations in chicken fed SeNPs; however, albumin content was not affected. Also Mohapatra et al. (2014) observed linear and quadratic increase in serum total protein and globulin levels in layer grower birds fed diet supplemented with SeNPs.

Data connected with serum lipid profile showed that both examined SeNPs administration routes and their interaction were significantly affected in broiler chicks (Table 6). While serum levels of total cholesterol (TC) and triglyceride (TG) were decreased in the in ovo injected groups compared to the non-injected group, the HDL-C level was increased. There was no effect of SeNPs injection on LDL-C level. In case of SeNPs dietary administration, serum TC and LDL-C levels were not significantly affected. On the other hand, feed supplementation with SeNPs had a significant impact on serum TG and HDL-C levels, with the lower TG content and higher HDL-C level observed in the SeNPs-treated group compared to the nonsupplemented one. The interaction between the two delivery routes was significant for both $\mathrm{TG}$ and HDL-C levels. The lowest TG levels were stated for R2 $(0 \times 10)$ and R4 $(5 \times 10)$ groups, while and the highest contents of HDL-C were observed in $\mathrm{R} 3(5 \times 10), \mathrm{R} 4(5 \times 10)$ and $\mathrm{R} 6(10 \times 10)$ groups. Furthermore serum TC and LDL-C levels were not significantly affected by the interaction between the examined delivery routes. However, the lowest TC and LDL-C levels were recorded for R2 $(0 \times 10)$, $\mathrm{R} 4(5 \times 10)$ and R6 $(10 \times 10)$ groups. These results are partially consistent with the results of Saleh (2014) who found significant decrease in plasma TG but also TC levels in broiler chickens fed diet with SeNPs addition, while plasma HDL-C content was increased. Simultaneously Elsaid (2015) found significant increase in plasma HDL-C level in chicks fed diet with SeNPs supplementation at a dose of $40 \mathrm{ppb}$. The same authors stated also a significant decrease in plasma total lipids, TG, TC and LDL-C in the SeNPs-treated group. Radwan et al. (2015) also observed a significant decrease in plasma total lipids, TC and an increase in HDL-C as a result of SeNPs administration. In proportionate with these results, Yang et al. (2012) reported no significant difference in serum TC, TG and HDL-C levels in chicks fed diet supplemented with selenium.

Concerning liver function, serum alkaline phosphatase (ALP), alanine aminotransferase (ALT) and aspartate aminotransferase (AST) activities were analysed (Table 6). The obtained results indicated that the different routes of SeNPs administration had different effects on ALT, AST and ALP activities. The feed supplementation significantly affected ALT and AST activities ( $P<0.01$ for both enzymes) but not ALP activity, while the in ovo injection had no significant effect on these enzymes activities. The interaction between the delivery routes was significant $(P<0.01)$ only for ALT activity. The lowest values of ALT activity were recorded in R6 $(10 \times 10)$ and R4 $(5 \times 10)$ groups, while in the same groups the highest values of ALP were stated. Although some significant elevations in serum ALP, ALT and AST activities were found, the obtained values were in the normal rang according to the previous studies. The obtained finding is in line with the results of Yang et al. (2012), who reported no significant difference in serum AST and ALP activities in chicks fed diet supplemented with selenium. Also, Selim et al. (2015) indicated no significant effect on plasma ALT, AST and ALP activities in broiler chicks fed diet with SeNPs addition. In contrast the results obtained by Elsaid (2015) showed a significant increase in serum ALT and AST activities in chicks fed diet with 40 ppb SeNPs addition per kg. Also Mohapatra et al. (2014) observed linear and quadratic increase in serum AST activity inlayer grower birds fed diet supplemented with SeNPs, whereas ALP activity was decreased. On the other hand, Saleh (2014) noted significant decrease in plasma AST activity in birds fed SeNPs-supplemented diet.

Regarding kidney function, the obtained data revealed that there was no significant of SeNPs in ovo injection or feed supplementation on serum levels of uric acid and creatinine. Also the interaction between the two delivery routes was not significant. The insignificant effect on kidney 
function expressed by serum levels of uric acid and creatinine may indicate that no stressful condition so called 'toxicity state' was introduced in treated chicks. The above results are in agreement with Yang et al. (2012) who stated no significant different in urea levels in serum of chicks receiving additional selenium in the diet. On the other hand, Elsaid (2015) found a significant decrease in plasma uric acid and creatinine levels in chicks fed diet with SeNPs. In contrary Mohapatra et al. (2014) observed a quadratic increase in serum urea level of layer grower birds fed diet supplemented with SeNPs.

The serum $\mathrm{T}_{3}$ and glucose levels were also analysed (Table 6). The obtained results showed a significant effect of SeNPs feed supplementation on glucose serum concentration $(P<0.002)$, while no effect of in ovo injection was stated. The highest glucose levels were stated in R4 $(5 \times 10)$ and R6 $(10 \times 10)$ groups, while the lowest level was observed for R5 $(10 \times 0)$ group. On the other hand, $\mathrm{T}_{3}$ level was significantly $(P<0.04)$ increased in the group in ovo injected with SeNPs at a dose of $5 \mathrm{ppb}$. Also the SeNPs addition into the diet caused an increase in serum $\mathrm{T}_{3}$ levels $(P<0.006)$. The interaction between the two SeNPs delivery routes was also statistically significant $(P<0.001)$. In all treatments, except R5 $(10 \times 0), \mathrm{T}_{3}$ levels were higher in comparison to R1 $(0 \times 0)$ group. The significant elevations in serum glucose and $\mathrm{T}_{3}$ concentrations may be associated with the role of selenium as a structural component of 5'-deiodinase, which is a key enzyme participating in the $\mathrm{T}_{4}$ conversion to the active $\mathrm{T}_{3}$. In this line Elsaid (2015) found a significant increase in plasma $T_{3}$ and $T_{4}$ concentrations in birds fed diet supplemented with SeNPs. Similar trends were also illustrated by Choupani et al. (2014) who showed increased plasma $T_{3}$ levels and higher $\mathrm{T}_{3}: \mathrm{T}_{4}$ ratio in SeNPs supplemented group compared with groups supplemented with organic and inorganic selenium. In the study by Jianhua et al. (2000), Se-deficient chickens showed significant reduction in $\mathrm{T}_{3}$ levels and elevated $\mathrm{T}_{4}$ levels compared with Se-supplemented chickens. Contrariwise, Boostani et al. (2015) indicated no significant difference in plasma levels of $\mathrm{T}_{3}$ and $\mathrm{T}_{4}$ between birds fed diet with organic selenium, inorganic selenium and SeNPs under oxidative stress.

Antioxidant status. The results of serum antioxidant status including reduced glutathione (GSH) and malondialdehyde (MDA) contents and glutathione reductase (GSR) activity showed significant differences depending on SeNPs delivery route (Table 7). GSH level and GSR activity in serum

Table 7. Effect of in ovo injection and feed supplementation with selenium nanoparticles (SeNPs) on antioxidant status, immunoglobulins (IgG, $\operatorname{lgM}, \lg A$ and total Ig) contents and humoral immune response against Newcastle Disease Virus (NDV) of broiler chicks

\begin{tabular}{|c|c|c|c|c|c|c|c|c|c|}
\hline \multirow[t]{2}{*}{ Indices } & \multicolumn{3}{|c|}{ Antioxidant status } & \multicolumn{4}{|c|}{ Immunological status, $\mu \mathrm{g} / \mathrm{ml}$} & \multicolumn{2}{|c|}{$\begin{array}{l}\text { Humoral immune response, } \\
\text { antibody titer against NDV }\end{array}$} \\
\hline & $\mathrm{MDA}, \mu \mathrm{mol} / \mathrm{ml}$ & $\mathrm{GSH}, \mathrm{mg} / \mathrm{l}$ & $\mathrm{GSR}, \mathrm{mg} / \mathrm{ml}$ & $\lg A$ & $\lg M$ & $\lg G$ & total Ig & $1^{\text {st }}$ response & $2^{\text {nd }}$ response \\
\hline \multicolumn{10}{|c|}{$\begin{array}{l}\text { Main factors } \\
\text { in ovo injection (l) }\end{array}$} \\
\hline 0 & $0.238^{a}$ & $0.151^{b}$ & $0.166^{b}$ & 137 & $75.8^{c}$ & $908^{b}$ & $1122^{b}$ & $3.00^{\mathrm{ab}}$ & 1.45 \\
\hline 5 & $0.146^{b}$ & $0.188^{a}$ & $0.195^{\mathrm{ab}}$ & 138 & $132.5^{\mathrm{a}}$ & $920^{b}$ & $1191^{b}$ & $3.50^{\mathrm{a}}$ & 1.45 \\
\hline 10 & $0.183^{b}$ & $0.197^{a}$ & $0.220^{\mathrm{a}}$ & 150 & $104.8^{b}$ & $1034^{\mathrm{a}}$ & $1288^{a}$ & $2.17^{\mathrm{b}}$ & 1.48 \\
\hline$P$-value & 0.001 & 0.001 & 0.001 & 0.443 & 0.001 & 0.005 & 0.002 & 0.044 & 0.991 \\
\hline SEM & 0.01 & 0.01 & 0.01 & 7.72 & 7.08 & 23.47 & 25.88 & 0.33 & 0.20 \\
\hline \multicolumn{10}{|c|}{ feed supplementation (S) } \\
\hline 0 & $0.212^{\mathrm{a}}$ & $0.152^{b}$ & $0.161^{b}$ & $118^{b}$ & $94.2^{\mathrm{b}}$ & $856^{b}$ & $1068^{b}$ & $2.20^{\mathrm{b}}$ & 1.46 \\
\hline 10 & $0.166^{b}$ & $0.206^{a}$ & $0.226^{a}$ & $165^{\mathrm{a}}$ & $114.6^{\mathrm{a}}$ & $1052^{\mathrm{a}}$ & $1333^{a}$ & $3.57^{\mathrm{a}}$ & 1.47 \\
\hline$P$-value & 0.008 & 0.001 & 0.002 & 0.000 & 0.029 & 0.001 & 0.004 & 0.005 & 0.963 \\
\hline SEM & 0.01 & 0.01 & 0.01 & 6.30 & 5.78 & 19.17 & 21.13 & 0.27 & 0.17 \\
\hline \multicolumn{10}{|l|}{ Interaction $(\mathrm{I} \times \mathrm{S})$} \\
\hline $\mathrm{R} 1(0 \times 0)$ & $0.295^{\mathrm{a}}$ & 0.122 & $0.142^{d}$ & 106 & 75.7 & 800 & 981 & $2.67^{b}$ & 1.43 \\
\hline $\mathrm{R} 2(0 \times 10)$ & $0.180^{\text {bc }}$ & 0.180 & $0.190^{\mathrm{bc}}$ & 168 & 76.0 & 1016 & 1263 & $2.33^{b}$ & 1.47 \\
\hline $\mathrm{R} 3(5 \times 0)$ & $0.134^{c}$ & 0.167 & $0.170^{\text {cd }}$ & 115 & 125.0 & 804 & 1044 & $2.00^{b}$ & 1.43 \\
\hline $\mathrm{R} 4(5 \times 10)$ & $0.158^{\mathrm{bc}}$ & 0.209 & $0.219^{b}$ & 162 & 140.0 & 1036 & 1338 & $5.00^{\mathrm{a}}$ & 1.47 \\
\hline $\mathrm{R} 5(10 \times 0)$ & $0.205^{b}$ & 0.168 & $0.171^{\mathrm{cd}}$ & 135 & 82.0 & 963 & 1180 & $2.00^{b}$ & 1.50 \\
\hline $\mathrm{R} 6(10 \times 10)$ & $0.161^{b c}$ & 0.227 & $0.269^{a}$ & 165 & 127.7 & 1104 & 1397 & $2.33^{b}$ & 1.47 \\
\hline$P$-value & 0.007 & 0.644 & 0.048 & 0.393 & 0.110 & 0.378 & 0.552 & 0.030 & 0.991 \\
\hline SEM & 0.02 & 0.01 & 0.01 & 10.92 & 10.02 & 33.19 & 36.60 & 0.47 & 0.29 \\
\hline
\end{tabular}

MDA - malondialdehyde content; GSH - reduced glutathione content; GSR - glutathione reductase activity; SEM - standard error of means; ${ }^{a-c}-$ means with different superscripts within the same column for each main factor or interaction separately are significantly different $(P \leq 0.05)$ 
were significantly $(P<0.001$ for both parameters $)$ increased while MDA content was significantly $(P<0.001)$ decreased when SeNPs were in ovo injected. The same relationships were found for SeNPs feed supplementation $(P<0.008, P<0.001$ and $P<0.002$ for MDA and GSH levels and GSR activity, respectively). The significant interaction between routes of SeNPs delivery was found for MDA content and GSR activity. The highest values of GSR activity and GSH content were observed in birds from R6 $(10 \times 10)$ and R4 $(5 \times 10)$ groups and the lowest ones in R1 $(0 \times 0)$ group. On the other hand the highest values of MDA level were observed in birds from groups R1 $(0 \times 0)$ and R5 $(10 \times 0)$, while the lowest values of MDA were stated in birds from R3 $(5 \times 0)$ group.

The obtained results on serum antioxidant status shed light upon the selenium function as a major component of the antioxidant system which participates in controlling the body glutathione pool. The results clarify the vital roles of SeNPs in protecting cells from reactive oxygen species (ROS) abundance by reducing free radicals and lipid peroxidation products (Pilarczyk et al., 2012). The results are in close agreement with Jiang et al. (2009) who mentioned significant increase in plasma antioxidant enzymes activities in broilers fed diet with Se-methionine. Chen et al. (2013) showed also significant elevation in the serum activities of total superoxide dismutase (T-SOD) and glutathione peroxidase (GSH-Px), as well as in the ability to inhibit hydroxyl radical $\left(\mathrm{OH}^{-}\right)$and total antioxidant capacity (T-AOC) in chickens treated with selenium yeast. Moreover, the same authors showed significant decrease in the contents of MDA in the selenium yeast groups. Similarly, Cai et al. (2012) showed significant quadratic effect of SeNPs on serum MDA level, GSH-Px activity and free radical inhibition in broilers fed diet supplement with $0.30 \mathrm{mg} \mathrm{SeNPs} / \mathrm{kg}$ diet. Also, Mohamed et al. (2016) stated positive effects on plasma total antioxidant capacity of chickens fed diet supplemented with SeNPs.

Immunoglobulins and humoral immune response against Newcastle Disease Virus (NDV). In relation to immunoglobulins status and immune response against NDV, the main factors effects and their interaction were stated (Table 7). It was observed that SeNPs in ovo injection significantly affected immunoglobulins content $(P<0.001$, $P<0.005$ and $P<0.002$ for IgM, IgG and TIg respectively) and $1^{\text {st }}$ week antibody titer against
NDV $(P<0.04)$. The IgM content was the highest in birds with in ovo injection of SeNPs at a dose of $5 \mathrm{ppb}$, while in the non-injected group IgM content was the lowest. IgG and TIg levels were elevated only in birds with in ovo injection of SeNPs at a dose of $5 \mathrm{ppb}$. The $1^{\text {st }}$ week antibody titer against NDV was decreased in birds with in ovo injection of SeNPs at a dose of $10 \mathrm{ppb}$ in comparison to $5 \mathrm{ppb}$ SeNPs dose. The SeNPs feed supplementation exerted influence on all examined immunoglobulins $(P<0.0001$, $P<0.03, P<0.004$ and $P<0.005$ for $\operatorname{IgA}, \operatorname{IgM}$, IgG and TIg, respectively) and $1^{\text {st }}$ week antibody titer against NDV $(P<0.005)$ with higher values in treated group for all parameters. The interaction between two examined SeNPs routes of delivery was significant only for the $1^{\text {st }}$ week antibody titer against NDV.

The improvement in serum immunoglobulins levels and humoral immune response against NDV may be attributed to the important biological role of SeNPs in increasing the concentration of circulating $\mathrm{T}$ and $\mathrm{B}$ cells, which leads to an increase in leukocyte subpopulation and cellular phagocytic activity. This results are coordinated with Cai et al. (2012) who reported a significant quadratic effect of SeNPs supplementation on serum IgM in of broiler chicks. Also, Swain et al., (2000) reported a significant increase in antibody production against NDV in broiler chicks fed a combination of $150 \mathrm{IU} / \mathrm{kg}$ vitamin $\mathrm{E}$ and $0.1 \mathrm{ppm} \mathrm{Se}$ as $\mathrm{Na}_{2} \mathrm{SeO}_{3}$. Similar results were suggested by Levkut et al. (2009) who showed a significant elevation in serum IgM, CD44+ and $\mathrm{CD} 45+$ concentrations and $\mathrm{MHCII}+$ peripheral blood lymphocytes in broiler chicks fed diet containing increased dose of selenium.

\section{Conclusions}

It could be concluded that both the in ovo injection of selenium nanoparticles (SeNPs) on day 14 of embryogenesis and the feed supplementation with SeNPs, as well as the combination of these two examined routes of SeNPs delivery, improve post hatch productive performance, lipid profile and antioxidant and immunological status of broiler chicks. Based on the obtained results, the use of SeNPs may be recommended, especially in the form of in ovo delivery at a dose of $10 \mathrm{ppb} / \mathrm{egg}$ or in a combination of in ovo delivery at a dose of $5 \mathrm{ppb} / \mathrm{egg}$ and a feed additive at a dose of $10 \mathrm{ppb} / \mathrm{kg}$ ration, to improve production efficiency and the physiological and immunological status of hatched chicks. 


\section{References}

Allan W.H., Gough R.E., 1974. A standard haemagglutination inhibition test for Newcastle disease. (1). A comparison of macro and micro methods. Vet. Rec. 95, 120-123, https://doi. org/10.1136/vr.95.6.120

Bhanja S.K., Mandal A.B., Johri T.S., 2004. Standardization of injection site, needle length, embryonic age and concentration of amino acids for in ovo injection in broiler breeder eggs. Indian J. Poult. Sci. 39, 105-111

Biswas A., Mohan J., Sastry K.V.H., 2006. Effect of higher levels of dietary selenium on production performance and immune responses in growing Japanese quail. Br. Poult. Sci. 47, 511515, https://doi.org/10.1080/00071660600830629

Boostani A., Sadeghi A.A., Mousavi S.N., Chamani M., Kashan N., 2015. The effects of organic, inorganic, and nano-selenium on blood attributes in broiler chickens exposed to oxidative stress. Acta Sci. Vet. 43, 1264

Cai S.J., Wu C.X., Gong L.M., Song T., Wu H., Zhang L.Y., 2012. Effects of nano-selenium on performance, meat quality, immune function, oxidation resistance, and tissue selenium content in broilers. Poult. Sci. 91, 2532-2539, https://doi. org/10.3382/ps.2012-02160

Cantor A.H., Moorhead P.D., Musser M.A., 1982. Comparative effects of sodium selenite and selenomethionine upon nutritional muscular dystrophy, selenium-dependent glutathione peroxidase, and tissue selenium concentrations of turkey poults. Poult. Sci. 61, 478-484, https://doi.org/10.3382/ps.0610478

Chen G., Wu J., Li C., 2013.The effect of different selenium levels on production performance and biochemical parameters of broilers. Ital. J. Anim. Sci. 12, e79, https://doi.org/10.4081/ ijas.2013.e79

Choupani M., Moghadam P.Z., Kelidari H.R., Ghaz S., 2014. Influence of dietary selenium sources on thyroid hormone activation, tissue selenium distribution and antioxidant enzymes status in broiler chickens. Trends Life Sci. 3, 281-297

Duncan D.B., 1955. Multiple rang and multiple F-tests. Biometrics 11, 1-42, https://doi.org/10.2307/3001478

Ebeid T.A., Zeweil H.S., Basyony M.M., Dosoky W.M., Badry H., 2013. Fortification of rabbit diets with vitamin $\mathrm{E}$ or selenium affects growth performance, lipid peroxidation, oxidative status and immune response in growing rabbits. Livest. Sci. 155, 323-331, https://doi.org/10.1016/j.livsci.2013.05.011

Elsaid A.E., 2015. Influence of in-ovo injection with nanoparticles selenium (SeNPs) on growth performance, carcass yield and immune status of broiler chicks PhD Thesis. Damietta University, Faculty of Agriculture. Damietta (Egypt)

Heindl J., Ledvinka Z., Englmaierová M., Zita L., Tůmová E., 2010. The effect of dietary selenium sources and levels on performance, selenium content in muscle and glutathione peroxidase activity in broiler chickens. Czech J. Anim. Sci. 55, 572-578, https://doi.org/10.17221/2487-CJAS

Jamil Z., 2013. Effects of inorganic and nano form of selenium on growth performance and biochemical indices of mahseer (Tor Putitora). MPhil. Thesis. Department of Animal Sciences, Faculty of Biological Sciences, Quaid-i-Azam University, Islamabad (Pakistan)

Jiang Z., Lin Y., Zhou G., Luo L., Jiang S., Chen F., 2009. Effects of dietary selenomethionine supplementation on growth performance, meat quality and antioxidant property in yellow broilers. J. Agric. Food Chem. 57, 9769-9772, https://doi. org/10.1021/jf902411c

Jianhua H., Ohtsuka A., Hayashi K., 2000. Selenium influences growth via thyroid hormone status in broiler chickens. Br. J. Nutr. 84, 727-732, https://doi.org/10.1017/S0007114500002087
Keen C.L., Uriu-Adams J.Y., Ensunsa J.L., Gershwin M.E., 2004. Trace elements/minerals and immunity. In: M.E. Gershwin, P. Nestel, C.L. Keen (Editors). Handbook of Nutrition and Immunity. Humana Press. Totowa, NJ (USA), 117-140, https://doi.org/10.1007/978-1-59259-790-1_6

Khan K.U., Zuberi A., Nazir S., Fernandes J.B.K., Jamil Z., Sarwar H., 2016. Effectsof dietary selenium nanoparticles on physiological and biochemical aspects ofjuvenile Tor putitora. Turk. J. Zool. 40, 704-712, https://doi.org/10.3906/zoo-1510-5

Khan K.U., Zuberi A., Ullah I., Sajjad, 2015. Effects of graded level of dietaryL-ascorbyl-2-polyphosphate on growth performance and some haematological indices of juvenile mahseer (Tor putitora). Int. J. Agric. Biol. 17, 821-827, https://doi. org/10.17957//JAB/14.0023

Khazraie S.K., Ghazanfarpoor R., 2015. Effect of nano-selenium particles and sodium selenite on performance, glutathione peroxidase and superoxide dismutase of quail under heat stress. Int. J. Rev. Life. Sci. 5, 875-882

Levkut M., Revajová V., Levkutová M., Ševčíková Z., Herich R., Borutová R., Leng L., 2009. Leukocytic responses of broilers following dietary contamination with deoxynivalenol and/or treatment by dietary selenium supplementation. Br. Poult. Sci. 50, 181-187, https://doi.org/10.1080/00071660802710090

Mohamed H.S., Risk Y.S., Elslamony A.E., Soliman A.A., Ebrahim A.F., 2016. Study the relationship between selenium and heat shock proteins under heat stress for local Sinai chickens strain. Egypt. Poult. Sci. J. 36, 337-354, https://doi. org/10.21608/epsj.2016.33379

Mohapatra P., Swain R.K., Mishra S.K., Behera T., Swain P., Behura N.C., Sahoo G., Sethy K., Bhol B.P., Dhama K., 2014. Effects of dietary nano-selenium supplementation on the performance of layer grower birds. Asian J. Anim. Vet. Adv. 9, 641-652, https://doi.org/10.3923/ajava.2014.641.652

Mountzouris K.C., Tsitrsikos P., Palamidi I., Arvaniti A., Mohnl M., Schatzmayr G., Fegeros K., 2010. Effects of probiotic inclusion levels in broiler nutrition on growth performance, nutrient digestibility, plasma immunoglobulins, and cecal microflora composition. Poult. Sci. 89, 58-67, https://doi. org/10.3382/ps.2009-00308

NRC (National Research Council), 1994. Nutrient Requirements of Poultry. $9^{\text {th }}$ Revised Edition. The National Academies Press. Washington, DC (USA), https://doi.org/10.17226/2114

Peng D., Zhang J., Liu Q., Taylor E.W., 2007. Size effectof elemental selenium nanoparticles (Nano-Se) at supranutritional levels on selenium accumulation and glutathione S-transferase activity. J. Inorg. Biochem. 101, 1457-1463, https://doi. org/10.1016/j.jinorgbio.2007.06.021

Pilarczyk B., Jankowiak D., Tomza-Marciniak A., Pilarczyk R., Sablik P., Drozd R., Tylkowska A.,Skólmowska M., 2012. Selenium concentration and glutathione peroxidase (GSH$\mathrm{Px}$ ) activity in serum of cows at different stages of lactation. Biol. Trace Elem. Res. 147, 91-96, https://doi.org/10.1007/ s12011-011-9271-y

Radwan N.L., Salah Eldin T.A., EL-Zaiat A.A., Mostafa A.S.A., 2015. Effect of dietary nano-selenium supplementation on selenium content and oxidant stability in table eggs and productive performance of laying hens. Int. J. Poult. Sci. 14, 161-176, https://doi.org/10.3923/ijps.2015.161.176

Raza A., 2012. Effects of graded levels of dietary selenium supplementation on the growth of juvenile mahseer (Tor Putitora). MPhil. Thesis. Department of Animal Sciences, Faculty of Biological Sciences, Quaid-i-Azam University, Islamabad (Pakistan) 
Rozbicka-Wieczorek A.J., Szarpak E., Brzóska F., Śliwiński B., Kowalczyk J., Czauderna M., 2012. Dietary lycopenes, selenium compounds and fish oil affect the profile of fatty acids and oxidative stress in chicken breast muscle. J. Anim. Feed Sci. 21, 705-724, https://doi.org/10.22358/jafs/66143/2012

Saleh A.A., 2014. Effect of dietary mixture of Aspergillus probiotic and selenium nano-particles on growth, nutrient digestibilities, selectedblood parameters and muscle fatty acid profile in broiler chickens. Anim. Sci. Pap. Rep. 32, 65-79

Selim N.A., Radwan N.L., Youssef S.F., Salah Eldin T.A., Abo Elwafa S., 2015. Effect of inclusion inorganic, organic or nano selenium forms in broiler diets on: 2-Pysiological, immunological and toxicity statuses of broiler chicks. Int. J. Poult. Sci. 14, 144-155, https://doi.org/10.3923/ijps.2015.144.155

Suraï P.F., Dvorska J.E., 2002. Effect of selenium and vitamin E content of the diet on lipid peroxidation in breast muscle tissue of broiler breeder hens during storage. In: Proceeding of the Australian Poultry Science Symposium. Sydney (Australia), 14, 187-192

Swain B.K., Johri T.S., Majumdar S., 2000. Effect of supplementation of vitamin $E$, selenium and their different combinations on the performance and immune response of broilers. Br. Poult. Sci. 41, 287-292, https://doi.org/10.1080/713654938
Wang H., Zhang J., Yu H., 2007. Elemental selenium at nano size possesses lower toxicity without compromising the fundamental effect on selenoenzymes: Comparison with selenomethionine in mice. Free Radical Biol. Med. 42, 1524-1533, https:// doi.org/10.1016/j.freeradbiomed.2007.02.013

Yang Y.R., Meng F.C., Wang P., Jiang Y.B., Yin Q.Q., Chang J., Zuo R.Y., Zheng Q.H., Liu J.X., 2012. Effect of organic and inorganic selenium supplementation on growth performance, meat quality and antioxidant property of broilers. Afr. J. Biotechnol. 11, 3031-3036, https://doi.org/10.5897/ AJB11.3382

Zhang J., Wang X., Xu T., 2008. Elemental selenium at nano size (Nano-Se) as a potential chemopreventive agent with reduced risk of selenium toxicity: comparison with Semethylselenocysteine in mice. Toxicol. Sci. 101, 22-31, https://doi.org/10.1093/toxsci/kfm221

Zhou X., Wang Y., 2011. Influence of dietary nano elemental selenium on growth performance, tissue selenium distribution, meat quality, and glutathione peroxidase activity in Guangxi Yellow chicken. Poult. Sci. 90, 680-686, https://doi.org/10.3382/ ps.2010-00977 